\title{
Pore Structure, Fractal Features, and Oil Content Evaluation of Lacustrine Shale: A Case Study of First Member of Paleogene Shahejie Formation, NE China
}

\author{
Enze Wang $\mathbb{D}^{1},{ }^{1}$ Gang Chen, ${ }^{2}$ Hanqi Li, ${ }^{3}$ Yanchen Song, ${ }^{1}$ Jianwei Wang, ${ }^{2}$ Zhuoya Wu, \\ and Yue Feng 5 \\ ${ }^{1}$ School of Earth and Space Sciences, Peking University, Beijing 100871, China \\ ${ }^{2}$ Research Institute of Petroleum Exploration and Development, PetroChina Jidong Oilfield Company, Tangshan 063004, China \\ ${ }^{3}$ Department of Geological Sciences, Jackson School of Geosciences, University of Texas, Austin, Texas 78712, USA \\ ${ }^{4}$ Research Institute of Petroleum Exploration \& Development, China National Petroleum Corporation, Beijing 100083, China \\ ${ }^{5}$ School of Energy Resource, China University of Geosciences, Beijing 100083, China
}

Correspondence should be addressed to Enze Wang; wangenze9939@163.com

Received 16 April 2021; Revised 10 June 2021; Accepted 27 July 2021; Published 24 September 2021

Academic Editor: Keliu Wu

Copyright (c) 2021 Enze Wang et al. This is an open access article distributed under the Creative Commons Attribution License, which permits unrestricted use, distribution, and reproduction in any medium, provided the original work is properly cited.

The complex and heterogeneous pore structure and oil content of lacustrine shales introduce significant challenges in the exploration of shale petroleum systems. To further expand our geological understanding of lacustrine shales and provide guidance for hydrocarbon exploration, in this study, based on programmed and improved Rock-Eval pyrolysis, total organic content (TOC) measurements, scanning electron microscopy (SEM) observations, and $\mathrm{N}_{2}$ adsorption (NA) experiments, a systematic evaluation of the mineral composition, geochemical features, pore structure, and oil contents of the third member of the Paleogene Shahejie Formation (Es3) shale in the typical lacustrine hydrocarbon enrichment sag (Nanpu Sag, Bohai Bay Basin) is conducted. The fractal theory is selected to quantify the pore system's heterogeneity; also, the relationships between the pore structure parameters and the oil contents and mineral composition are revealed. Our results reveal the geochemical features of the Es3 shale are excellent, and thus, they can be classified as a set of high-quality source rocks (average TOC of $4.2 \%$, mainly type II kerogen, and in the mature stage). Based on the SEM and NA analyses, the intercrystalline pores dominate the pore system. Moreover, the mesopores contribute the most specific surface area (SA) and pore volume (PV) to the samples (average contribution rates of 74.7 and $75.0 \%$, respectively). The fractal dimensions have relatively strong positive correlations with PV and SA, which means more heterogeneous and complex pore structures provide more storage space and adsorption sites for shale oil accumulation. The clay mineral content is the most important factor which controls the pore structure parameter, and high clay content indicates high SA and PV. According to proposed numerical movable and adsorption hydrocarbon calculation models, the TOC content is the dominant factor controlling the movable and adsorption oil contents, but other factors' impact also cannot be ignored. Our study not only provides guidance for shale oil exploration in the study area but also broadens our understanding of the oil contents of lacustrine shale.

\section{Introduction}

Shale petroleum system exploration has attracted the attention of academic communities all over the world [1-4]. In traditional petroleum geology, shale is regarded as the source rocks and cap rocks, which is not the exploration target. However, with technology improved, the shale petroleum system is seen as the successor for further energy supplement. Compared with conventional petroleum systems (conventional sandstone reservoirs), shale petroleum systems are characterized by self-generated and self-retained reservoirs, which means less hydrocarbon loss through petroleum migration and great resource potential [5]. Owing to the selfgeneration and short migration distances that characterize 
shale petroleum systems, it is important to accurately calculate the moveable and retention oil for resource evaluation and sweet spot prediction [6, 7]. Meanwhile, the oil and gas are stored in the nanoscale micropores in the shale $[8,9]$, and these nanoscale pore-throat structures pose a significant challenge in shale oil and gas exploration and development. Therefore, a clear understanding of the geometrical and geological features of the pore system is of great significance to the exploration of shale petroleum systems [10-12].

At present, several techniques are used to quantify the oil content and pore system. For oil content, the traditional Rock-Eval method is a useful tool for measuring the oil content of shales [13], and the thermally desorbed hydrocarbons at $300^{\circ} \mathrm{C}\left(S_{1}\right)$ are referred to as the oil content. However, in the oil generation window, a large amount of macromolecular bitumen and oil occurs in the adsorbed state within the $S_{2}$ peak [14-16], and using $S_{1}$ to assess the shale oil content may result in errors. For solving this problem, the improved Rock-Eval method was proposed by [17], this method corrects for the adsorbed hydrocarbons, thus, providing a more reliable oil content parameter, that is, the total oil yield (TOY) and movable and adsorbed oil content, which makes it a better method for shale oil content evaluation. Another important question for shale is the storage space for oil, and molecular dynamics is the frequently applied means to evaluate accumulation mechanisms for oil in nanopores [18]. Besides the storage behavior, the pore system is also significant for oil storage, for pore system, scanning electron microscopy (SEM), mercury intrusion capillary pressure (MIP) experiments, $\mathrm{N}_{2}$ gas adsorption (NA) experiments, and nuclear magnetic resonance (NMR) are well applied in this field [7, 12, 19]. Owing to its efficiency and low cost, the NA is one of the most common experiments used to measure the pore structure and the relevant parameters, such as the pore volume (PV), specific surface area (SA), and pore size distribution (PSD).

The fractal theory was proposed by Mandelbrot et al. [20] to describe the self-similarity of items; since then, [21] have reported that reservoir pore networks have a fractal nature, and the fractal theory has been widely used to quantify the self-similarity, complexity, and irregularity of the pore networks of sandstones, carbonates, and shales [22].

The Nanpu Sag is a typical lacustrine hydrocarbonenrichment sag in the Bohai Bay Basin. In 2020, significant breakthroughs were achieved in shale oil exploration in the Upper Paleogene Shahejie Formation (Es) [23], which exhibits an excellent resource potential as an unconventional petroleum system. However, there is still a knowledge gap in shale oil research, which restricts further exploration. Therefore, a comprehensive and systematic evaluation of the pore structure and oil retention of the shale is urgently needed and can effectively reduce the exploration risk for the Nanpu Sag.

In this study, we selected the third member of the Paleogene Shahejie Formation (Es3) in the Nanpu Sag as a case study; programmed Rock-Eval pyrolysis and total organic carbon (TOC) measurements were selected to analyze the geochemical features of the Es3 shale. The improved RockEval pyrolysis method was used to establish a numerical model for calculating the movable and adsorption oil contents. X-ray diffraction (XRD) analysis was used to quantify the mineral compositions, and the pore structure was investigated using SEM observations and NA. The objectives can be summarized as follows: (1) to systemically describe the mineral compositions, geochemical features, and pore structures of the shales; (2) to use the fractal dimension to quantify the complex and heterogeneous pore structures; (3) to establish a numerical model for calculating the movable and adsorbed oil contents; and (4) to determine the relationships between the mineral composition, pore structure, and oil contents.

Our research accurately depicts the oil content of Es3 shale in the study area, movable, and adsorption oil is quantified, and the numerical calculation models are constructed; meanwhile, we systematically analyze the pore system of Es3 shale and further discuss the controlling factors of oil content and pore system. The results of this study provide a solid reference for shale oil exploration in the Nanpu Sag and further expand geological understandings about lacustrine shales.

\section{Geologic Background}

The Bohai Bay Basin, located in eastern China, is a famous Mesozoic-Cenozoic faulted basin with abundant hydrocarbon resources (Tian et al., 2014). The Bohai Bay Basin has a strong spatial heterogeneity, including a series of subbasins. The Nanpu Sag is located in the northern part of the Huanghua subbasin in the center of the Bohai Bay Basin (Figure 1(a)), and it is a typical lacustrine petroliferous sag in eastern China [24]. The area of the Nanpu Sag is approximately $1932 \mathrm{~km}^{2}$, and it contains eight structural belts divided by a fault system (Figure 1(a)) $[25,26]$. The Gaoliu Fault is located in the center of the sag and separates the sag into two parts. There are three structural belts in the north (the Gaoshangpu, Laoyemiao, and Liuzan structural belts) and five in the south (the Nanpu no. 1-5 structural belts) $[27,28]$. The structural belts and subsags are distributed alternately, which is conducive to the migration and accumulation of the hydrocarbons generated by the source rocks in the sag to adjacent structural belts [24].

Since the Paleogene, the sag has entered a syn-rift stage, the lake has become enlarged, and a series of high-quality source rocks and sedimentary reservoirs (Es) have formed, which provide favorable conditions for hydrocarbon accumulation. From bottom to top, the strata are the Shahejie, Dongying (Ed), Guantao (Ng), Minghuazhen (Nm), and Quaternary (Q) sediments (Figure 1(b)) [29]. Owing to the enlarged lake and humid sedimentary environment [30], several high-quality source rock units were formed. The first and third members of the Paleogene Shahejie Formation include a series of black and dark gray shales, which are the main source rocks and contribute most of the hydrocarbon in the Cenozoic petroleum system [31]. Therefore, the Shahejie Formation is the main target for deep and unconventional petroleum exploration. The study area and target formation are the Gaoshangpu Structural Belt and Es3, respectively. 


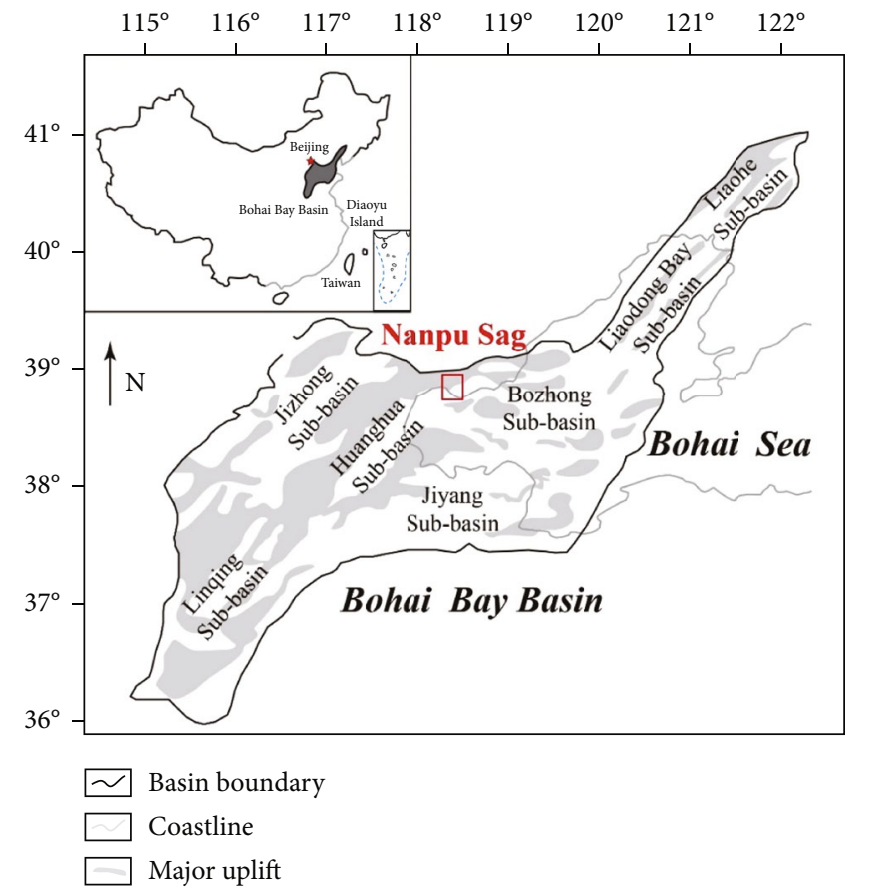

(a)

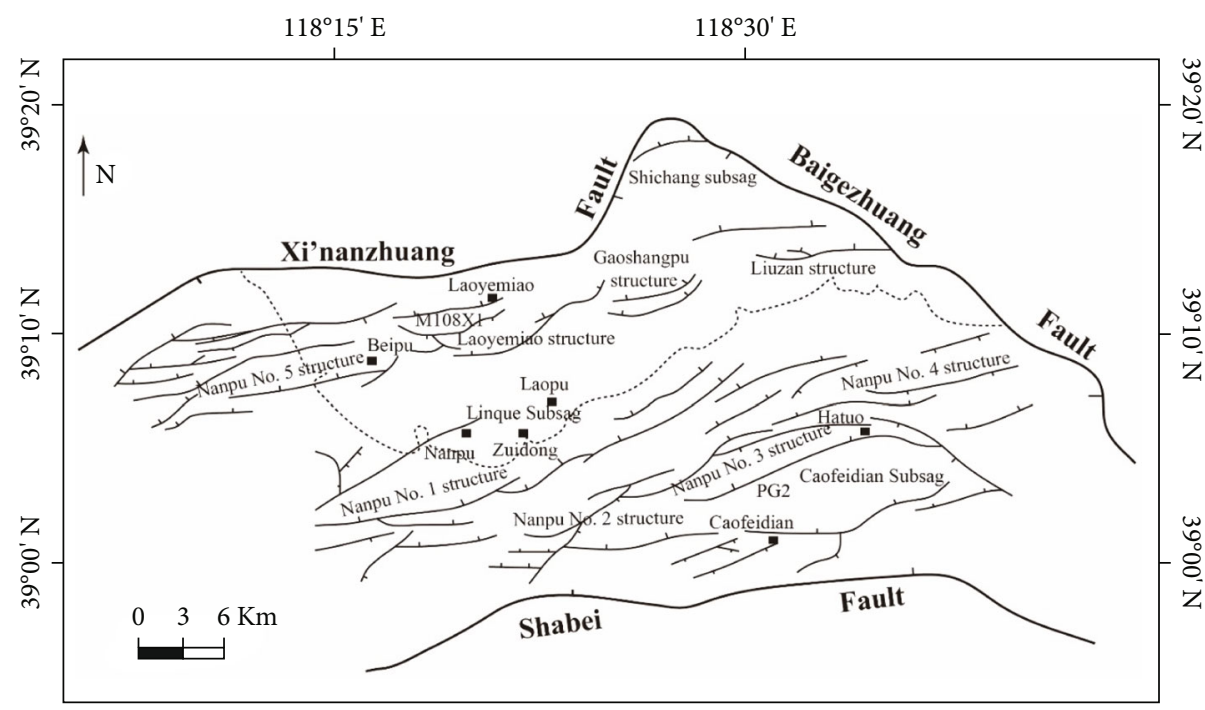

- Fault

- Town location

Constline

(b)

Figure 1: Continued. 


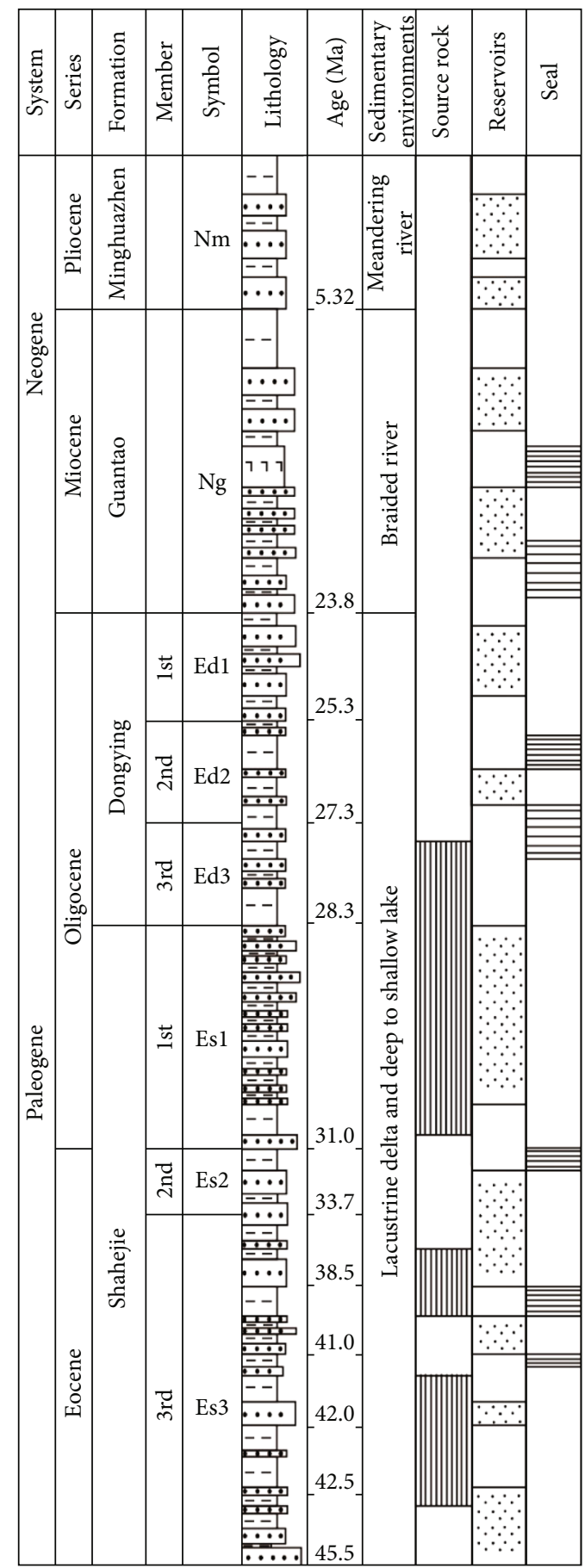
-. Sandstone
-- Mudstone
$\neg \neg$ Volcanic rock

(c)

FIgure 1: Comprehensive geological figure of the Nanpu Sag (from [28]). (a) The locations and distribution of subbasin of the Bohai Bay Basin. (b) The plane geological figure to show structural belts of the Nanpu Sag. (c) Columnar strata section of the Nanpu Sag.

\section{Data and Methods}

3.1. Samples and Experiments. To determine the mineral composition and geochemical features of the Es 3 shale, 55 sets of data including XRD, TOC content, and programmed RockEval analysis were collected. Among them, seven samples were selected for improved Rock-Eval, SEM, and NA measurements to further quantify the pore structure and oil retention features. 
Programmed Rock-Eval pyrolysis was conducted using a Rock-Eval II instrument. The $S_{1}$, the remaining hydrocarbon generation potential $\left(S_{2}\right)$, and the maximum pyrolysis yield $\left(T_{\max }\right)$ were obtained from this experiment [32]. The TOC content analyses were conducted using a LECO CS-400 instrument. The details of the improved Rock-Eval pyrolysis method are introduced in [17].

To determine the mineral compositions of the samples, XRD analyses were performed using a D8 DISCOVER Xray diffractometer. Seven samples were chosen for SEM analysis, which was conducted using a QUANTA 200 scanning electron microscope (accelerating voltage of $20 \mathrm{kV}$ ). The low-pressure NA experiments were conducted using a Quadrasorb $^{\text {TM }}$ SI surface area and a pore size analyzer. The Brunauer-Emmett-Teller (BET) model was used to calculate the SA, and the Barrette-Joyner-Halenda (BJH) model was used to describe the PSD of the shale. Based on Wheeler's theory, the PSD, PV, and SA can be directly calculated using the cylindrical pore model based on the NA isothermal curves [33].

3.2. Calculation Models of Movable and Adsorption Oil. Based on the improved Rock-Eval pyrolysis results, several parameters were obtained, including the movable hydrocarbons $\left(S_{1-1}+S_{1-2}\right)$, adsorbed hydrocarbons $\left(S_{2-1}\right)$, and cracking hydrocarbons $\left(S_{2-2}\right)$. The corresponding temperatures are $200,350,450$, and $600^{\circ} \mathrm{C}$, respectively. Therefore, based on the improved Rock-Eval pyrolysis data for the samples, the TOY can be calculated using the following equation [17].

$$
\mathrm{TOY}_{m}=S_{1-1}+S_{1-2}+S_{2-1} \text {. }
$$

TOY $_{m}$ is the TOY calculated from the measured data (mg HC/g rock); and $S_{1-1}, S_{1-2}$, and $S_{2-1}$ are the parameters obtained from the improved Rock-Eval pyrolysis analysis (mg HC/g rock).

For samples without improved Rock-Eval pyrolysis data, it is difficult to accurately describe the adsorbed hydrocarbon using routine Rock-Eval pyrolysis tests. However, the samples from the study area have a relatively consistent kerogen type (type II, see details in Section 4.2). We assume that the hydrocarbon adsorption capacity of the kerogen depends on the type and quantity of kerogen. Thus, for the same kerogen type, the quantity of kerogen determines the hydrocarbon adsorption capacity. We selected the TOC content as the index to characterize the quantity of kerogen. Based on the improved and programmed Rock-Eval pyrolysis data for the seven samples, the relationship between the calculated adsorbed hydrocarbons and the TOC content was analyzed, which revealed a good positive correlation $\left(R^{2}=0.92\right)$. Therefore, the numerical model used to calculate the $S_{a}$ in the Nanpu Sag is described by

$$
\mathrm{TOY}_{m}-S_{1}=S_{a}=1.906 \times \mathrm{TOC}-0.5746 .
$$

$S_{1}$ is the free hydrocarbon obtained by programed RockEval pyrolysis (mg HC/g rock); $S_{a}$ is the calculated adsorbed hydrocarbons (mg HC/g rock); TOC is the TOC content of the shale $(\%)$.
Meanwhile, the movable hydrocarbon is the most important index for shale oil exploration; based on improved Rock-Eval pyrolysis experiments, the movable hydrocarbons can be calculated, there is an excellent correlation relationship between the $S_{1}$ value obtained by programmed Rock-Eval pyrolysis testing $\left(R^{2}=0.99\right)$, and the calculated movable hydrocarbon $\left(S_{1 c}\right)$ can be obtained by

$$
S_{1 c}=1.4427 \times S_{1}+0.1 \text {. }
$$

3.3. NA Fractal Calculation Methodology. Several methods have been proposed for calculating the fractal dimension [33]. For NA experiments, the most common model used to obtain the fractal dimension is the Frenkel-Halsey-Hill $(\mathrm{FHH})$ model $[34,35]$, and the calculation principle of which is shown in

$$
\ln \left(\frac{V}{V_{0}}\right)=C+K \ln \left(\ln \left(\frac{P_{0}}{P}\right)\right)
$$

In Eq. (5), $V$ is the $\mathrm{N}_{2}$ gas adsorption volume at pressure $P$; and $V_{o}$ is the volume of a single molecule layer. $P_{0}$ is the gas saturation pressure, and $P$ is the equilibrium pressure. $C$ is a constant, and $K$ is the slope of Eq. (5). Theoretically, when the pore network is fractal, $\ln \left(V / V_{0}\right)$ and $\ln \left(\ln \left(P_{0} /\right.\right.$ $P)$ ) should exhibit a linear relationship [36]. Based on the $\mathrm{BJH}$ model, the relative pressure can be transformed into the pore size; therefore, the $K$ values of the different pore systems can be calculated. According to the classification scheme of the International Union of Pure and Applied Chemistry (IUPAC), the pores in shale can be divided into three categories based on pore size: micropores $(<2 \mathrm{~nm})$, mesopores $(2-50 \mathrm{~nm})$, and macropores (>50 nm) [37]. The fractal dimension can be obtained using

$$
D=K+3 \text {. }
$$

\section{Results}

4.1. Mineralogy. Based on the previous three component classification scheme and the structure of shale, the Es3 shale can be classified into three types [38]: argillaceous shale (A), mixed shale (MS), and siliceous shale (S). Among them, MS is the most common type of shale (Figure 2). About $90 \%$ of the samples plot in the MS field, and only one and four samples plot in the A and S type fields, respectively.

The XRD data show that clay minerals and siliceous minerals (quartz and feldspar) are the two main types of minerals, accounting for 30 to $52 \%$ (average $43.4 \%$ ) and 22 to $59 \%$ (average $38.3 \%$ ), respectively. In siliceous minerals, quartz processes a larger proportion, which ranges from 15 to $38 \%$ (average 23.5\%); and feldspar content varies from 7 to $32 \%$ (average value $14.8 \%$ ). The amount of carbonate is relatively small (4 to $38 \%$, average $18.6 \%$ ).

4.2. Geochemical Characteristics. The TOC content is one of the most important parameters for evaluating the hydrocarbon generation potential since a good hydrocarbon generation potential is the basis of shale oil reservoir 


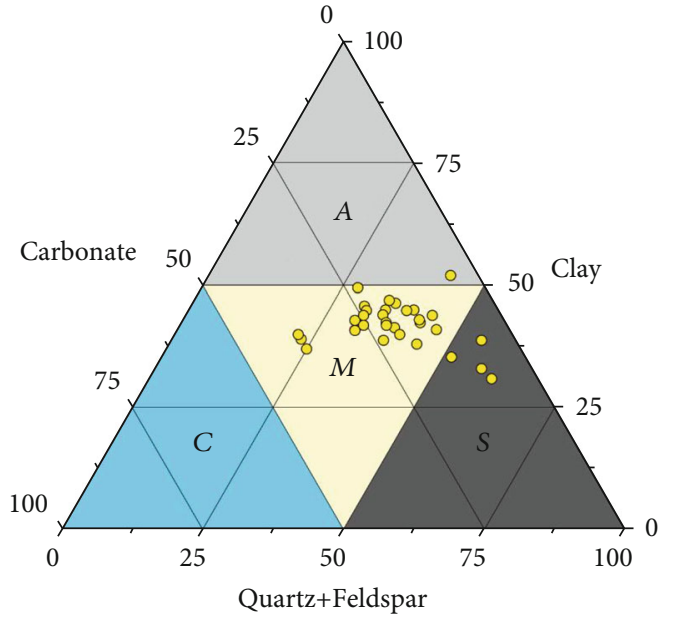

Figure 2: Triangular figure exhibiting mineral composition and classification of Es3 shale.

accumulation [38-40]. The TOC content of the Es3 shale ranges from 0.4 to $11.9 \%$, with an average of $4.2 \%$. In general, all of the samples have high TOC contents. The $S_{1}+$ $S_{2}$ values vary from 0.68 to $35.43 \mathrm{mg} \mathrm{HC/g}$ rock, with an average of $14.83 \mathrm{mg} \mathrm{HC/g}$ rock. The hydrogen index $\left(H_{I}=S_{2} / \mathrm{TOC} \times 100\right)$ can also be obtained from the TOC content and the Rock-Eval parameters. The $H_{I}$ values range from 145.8 to $516.6 \mathrm{mg} \mathrm{HC/g}$ TOC, with an average of $330.7 \mathrm{mg} \mathrm{HC} / \mathrm{g}$ TOC. Based on the lacustrine source rock evaluation standard proposed by [41] (Figure 3) [41], most samples of Es3 shale can be classified as good source rocks. This indicates that the Es3 source rocks have a significant hydrocarbon generation capability, which is consistent with the results of previous studies [28].

By using the Eqs. (2) and (3), the $S_{a}$ and $S_{1 c}$ can be calculated, the $S_{a}$ ranges from 0.11 to $22.05 \mathrm{mg} \mathrm{HC} / \mathrm{g}$ rock, the average value is $7.40 \mathrm{mg} \mathrm{HC/g}$ rock, and the $S_{1 c}$ varies from 0.19 to $5.78 \mathrm{mg} \mathrm{HC/g}$ rock (average value $2.19 \mathrm{mg}$ $\mathrm{HC} / \mathrm{g}$ rock).

Kerogen is the hydrocarbon generation material in the source rocks, and the kerogen type determines whether the source rock undergoes oil production or gas production [42]. $H_{I}$ and $T_{\max }$ are two parameters used to identify the kerogen type [43], and Figure 4 presents a plot of $H_{I}$ versus $T_{\max }$, which shows that most of the samples plot in the typeII kerogen field, and only one sample plots on the boundary line between type-II and type-III kerogen.

Another key parameter for source rock evaluation is thermal maturity, and $T_{\max }$ is a reliable index used to quantify source rock maturity [44]. The $T_{\max }$ values of Es3 shale range from 428 to $447^{\circ} \mathrm{C}$. This indicates that all of the samples are in the oil generation window, which is favorable for shale oil accumulation.

The Es3 shale from Qikou Sag, which is a mature shale oil exploration area [45], is selected to compare. The average TOC content and $S_{1}+S_{2}$ value of Es3 shale in Qikou Sag are $1.43 \%$ and $10.8 \mathrm{mg} \mathrm{HC/g}$ rock. The main kerogen type is type-II kerogen and can be identified in the mature stage [46]. Overall, the Es3 shale in the Nanpu Sag possesses a

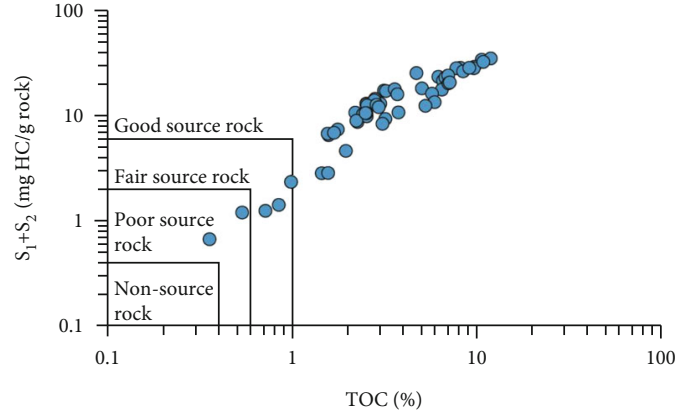

Figure 3: Organic matter abundance evaluation of Es3 shale.

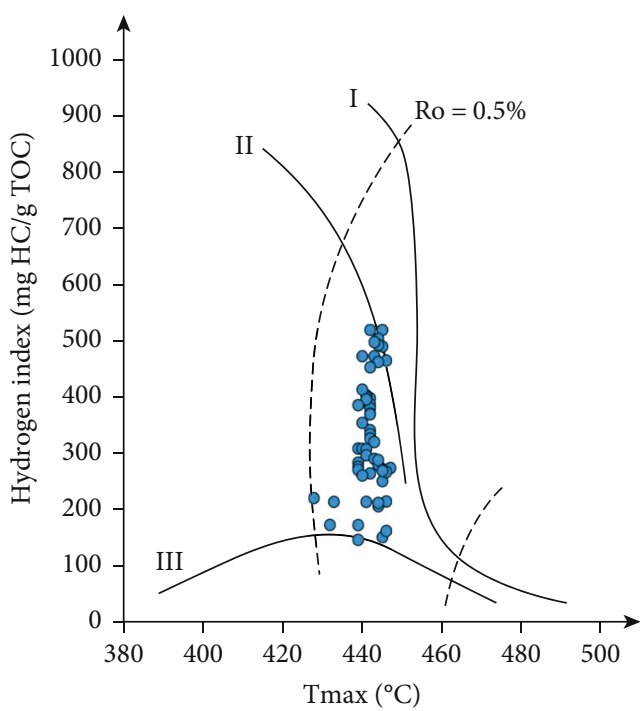

Figure 4: Kerogen type assessment of Es3 shale (ranges are from [43]).

similar kerogen type and thermal maturity, but higher TOC content and hydrocarbon generation potential, therefore, the Es3 shale of the Nanpu Sag has better exploration potential for shale oil.

\subsection{Pore System}

4.3.1. Pore Morphology. Based on the SEM observations, three types of pores were identified in the Es3 shale reservoirs: intercrystalline pores, intragranular pores, and microfractures. Organic pores, which have been widely observed in other petroliferous basins, such as the Longmaxi Formation in the Sichuan Basin [12], were not detected in the study area.

The intercrystalline pores in the Es3 shale usually occur in the spaces between the clay minerals and pyrite (Figures 5(a), 5(b), 5(e), and 5(h)). The pore size has a wide range, varying from tens of nanometers to several microns. The shape of the pores is a general disorder, and there are a variety of pore forms, including triangular, slits, and irregular multilateral pores. The intercrystalline pores can occur in the spaces between the clay minerals (Figure 5(h)), space between the round-elliptic pyrite crystals, and the spaces between the clay minerals and the edges of grains (quartz). 


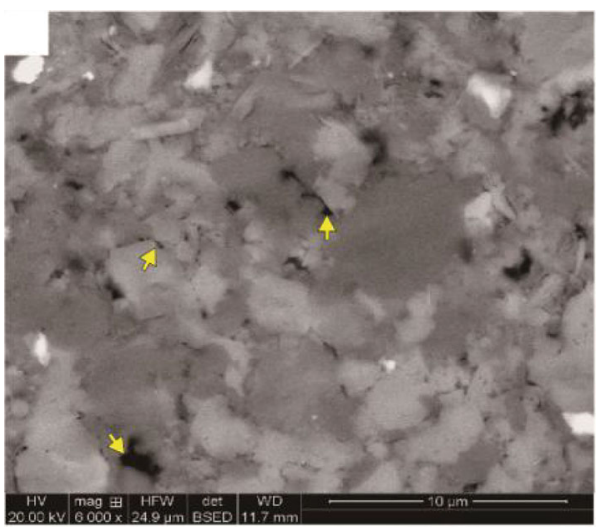

(a)

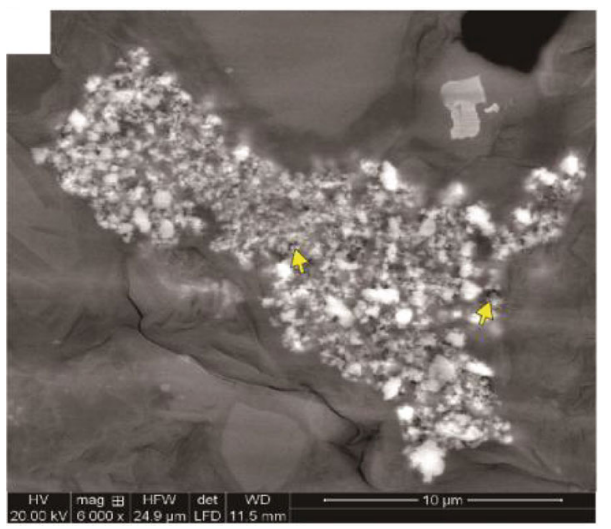

(c)

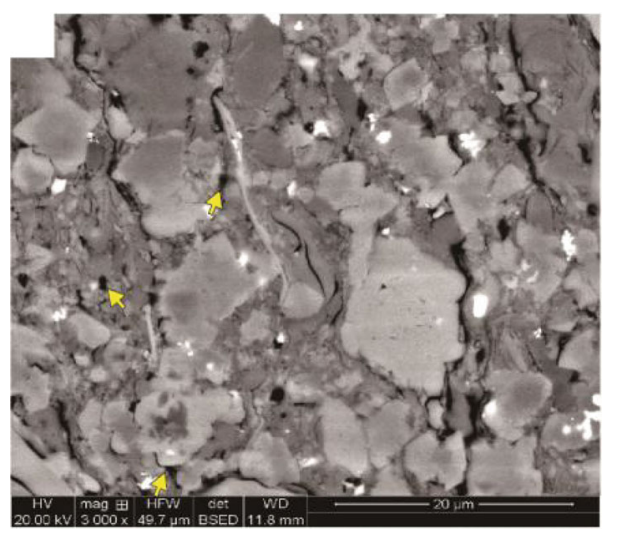

(e)

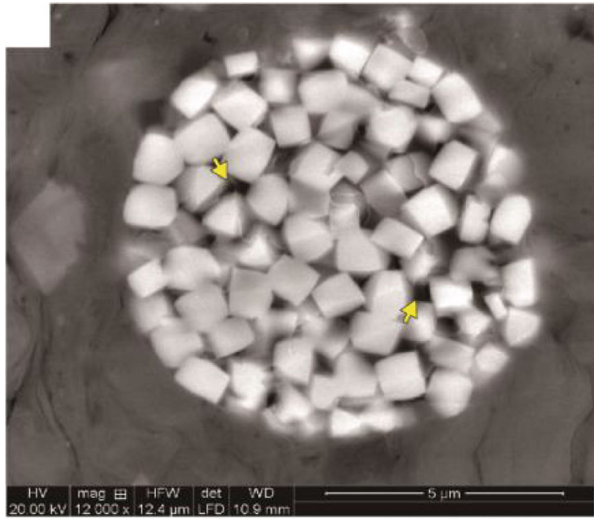

(b)

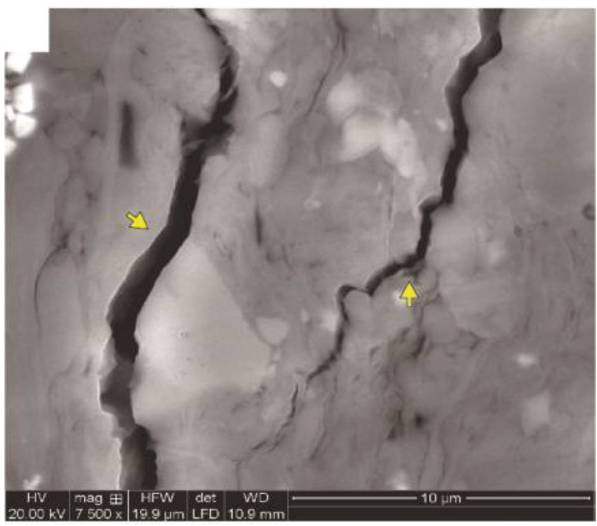

(d)

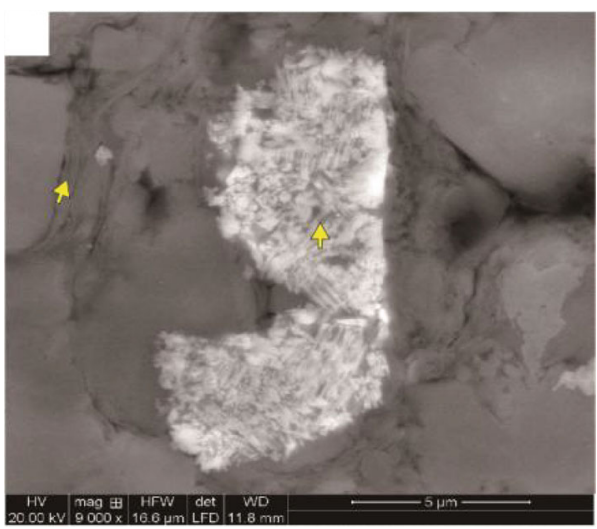

(f)

FIgURE 5: Continued. 


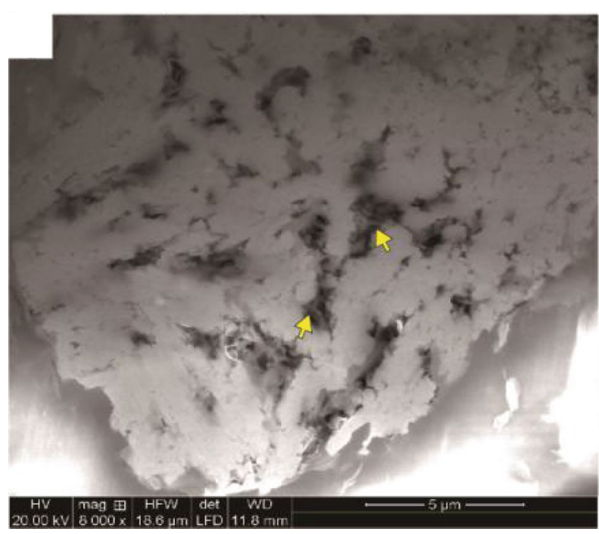

(g)

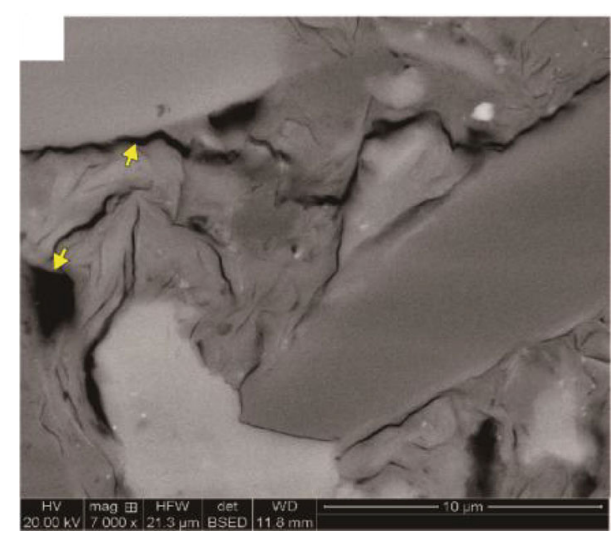

(h)

Figure 5: SEM observation reflecting the pore system of Es3 shale. (a) $4641 \mathrm{~m}$, intercrystalline pores of clay minerals. (b) $4635 \mathrm{~m}$, intercrystalline pores within round-elliptic pyrite. (c) $4640 \mathrm{~m}$, intragranular pores formed by pyrite dissolution. (d) $4635 \mathrm{~m}$, structural microfractures. (e) $4636 \mathrm{~m}$, intercrystalline pores of clay minerals and the edge of quartz. (f) $4636 \mathrm{~m}$, intercrystalline pores of clay minerals and intragranular pores formed by pyrite dissolution. (g) $4639 \mathrm{~m}$, intragranular pores formed by feldspar. (h) $4639 \mathrm{~m}$, intercrystalline pores of clay minerals and non-structural microfractures.

The boundaries between the clay minerals and quartz often contain intercrystalline and intergranular pores, and these pores often extend to the edges of the grains (Figures 5(a) and $5(\mathrm{e}))$. In the Es3 shale, the intercrystalline pores are well developed and are the main type of pore in the pore system.

Intragranular pores were commonly detected in the study area. These pores are formed by the dissolution of unstable minerals; therefore, they usually exhibit irregular shapes and are approximately dozens of nanometers to several micrometers in size. For some samples, the intragranular pores were observed with the unstable pyrite (Figures 5(c) and 5(f)), and for other samples, the intragranular pores were formed by feldspar dissolution (Figure 5(g)).

The microfractures can be classified as structural and nonstructural microfractures based on their formation mechanisms. The microfractures formed by structural stress exhibit longer extensions and greater widths, while the nonstructural microfractures exhibit shorter lengths and smaller widths [33]. Both structural and nonstructural microfractures were observed in the Es3 shale (Figures 5(a), 5(d), $5(\mathrm{e})$, and $5(\mathrm{~h}))$. The structural microfractures exhibit an irregular appearance, but the nonstructural microfractures appear on the boundaries between the clay minerals and quartz. All of these microfractures can improve the hydrocarbon storage and migration capability of the shales, especially the structural microfractures, which make a significant contribution to hydrocarbon migration.

4.3.2. Pore Structure Characteristics. NA experiments are a reliable technique for quantifying the pore-throat characteristics of shales. Based on the isothermal curve classification scheme proposed by the IUPAC, the curves for the Es3 shale are typical type IV reverse $S$ shape curves (Figures 6(a) and 6(c)). When the relative pressure is low, the adsorption line changes slowly and is convex, indicating that there is a certain number of micropores in the shale. As the relative pressure increases (approximately 0.4), the adsorption and desorption lines are obviously separated, forming different types of hysteresis loops, indicating the existence of different amounts of mesopores. When the relative pressure is high, the adsorption curve increases rapidly and is concave, indicating that there are macropores in the reservoir.

According to the IUPAC shape classification for the hysteresis loops, overall, the hysteresis loops of the shales from the study area are a mixture of types $\mathrm{H}_{2}$ and $\mathrm{H}_{3}$, which indicates that there are ink bottle-shaped, slit-shaped, and parallel plate-shaped pores in the shales. There are two types of hysteresis loops in the study area, for type I reservoirs, the hysteresis loop is closer to type $\mathrm{H}_{3}$, and for type II reservoir is more inclined toward type $\mathrm{H}_{2}$.

Using the $\mathrm{BJH}$ model, the pore size distribution, surface area, and pore volume of the different pore sizes were calculated. The plots of $\mathrm{dV}$ versus pore size show the amounts of pores. The type I shales are mainly dominated by micropores and mesopores (pore size $<10 \mathrm{~nm}$; Figure 6(b)). In contrast, the type II shale not only has a large number of micropores but it also has more mesopores with large diameters (pore size $>10 \mathrm{~nm}$ ), and it also has a considerable amount of macropores (Figure 6(d)). The surface area of the Es3 shale ranges from 0.612 to $2.703 \mathrm{~m}^{2} / \mathrm{g}$, with an average value of $1.145 \mathrm{~m}^{2} / \mathrm{g}$. The total pore volume varies from 0.281 to $0.984 \mathrm{~cm}^{3} / 100 \mathrm{~g}$, with an average value of $0.411 \mathrm{~cm}^{3} / 100 \mathrm{~g}$. The pore structure parameters are shown in Table 1. Our results show that type II has the highest surface area and pore volume. Furthermore, the mesopores contribute most of the surface area and pore volume in all of the samples, with average contribution rates of 74.7 and $75.0 \%$, respectively. The micropores have little impact on the pore volume (average contribution rate of $5.9 \%$ ), but they contribute some of the surface area (average 23.8\%). In contrast, the macropores contribute a considerable amount of the pore volume (average 19.2\%), but they have little influence on the surface area. 
(a1)

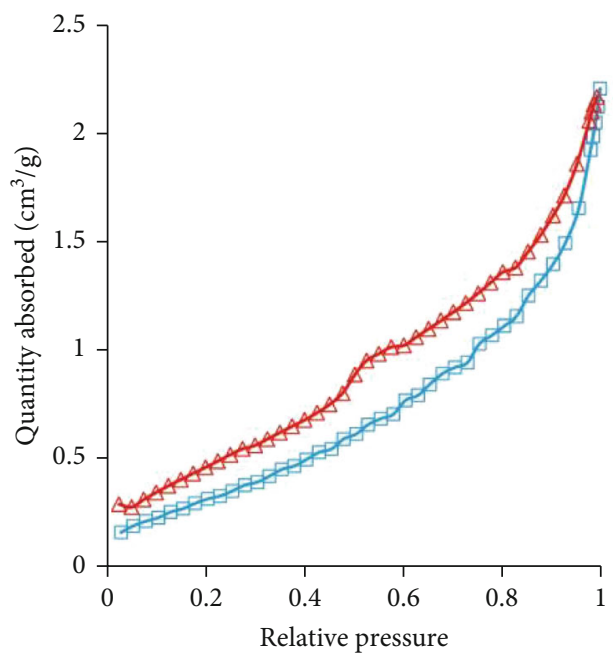

(b1)

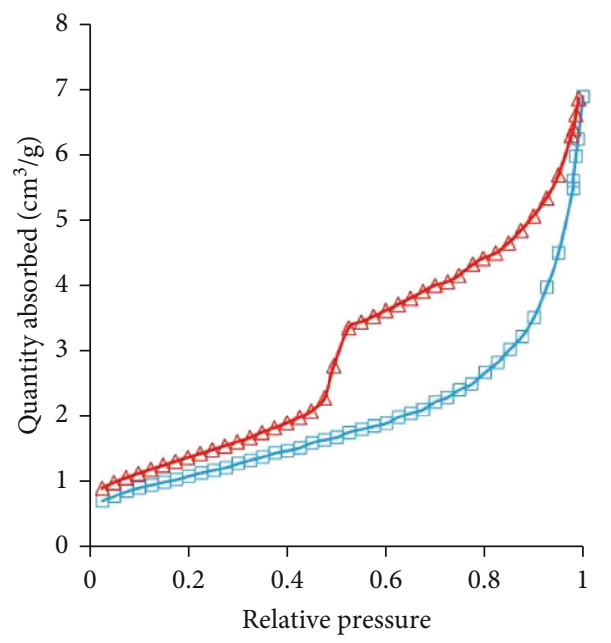

(a2)

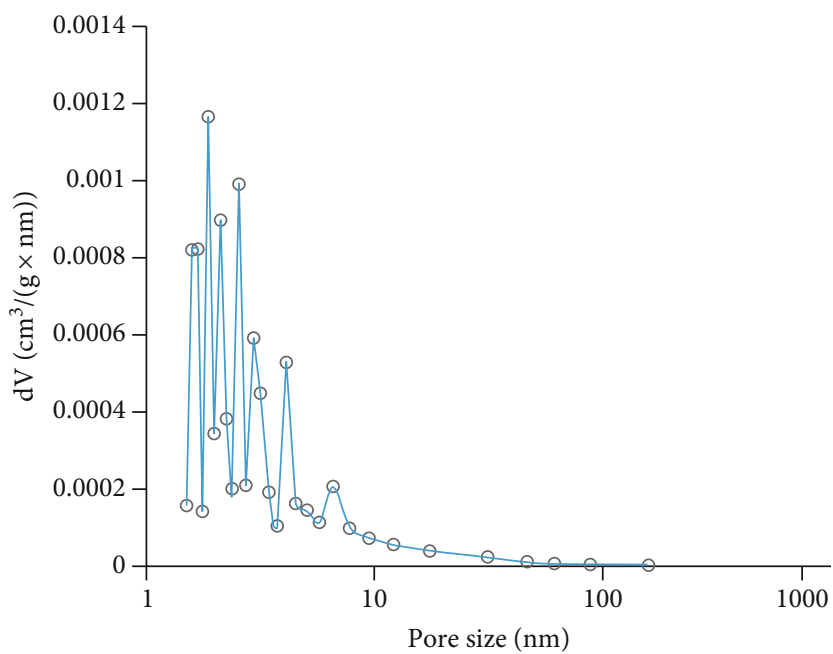

(a)

(b2)

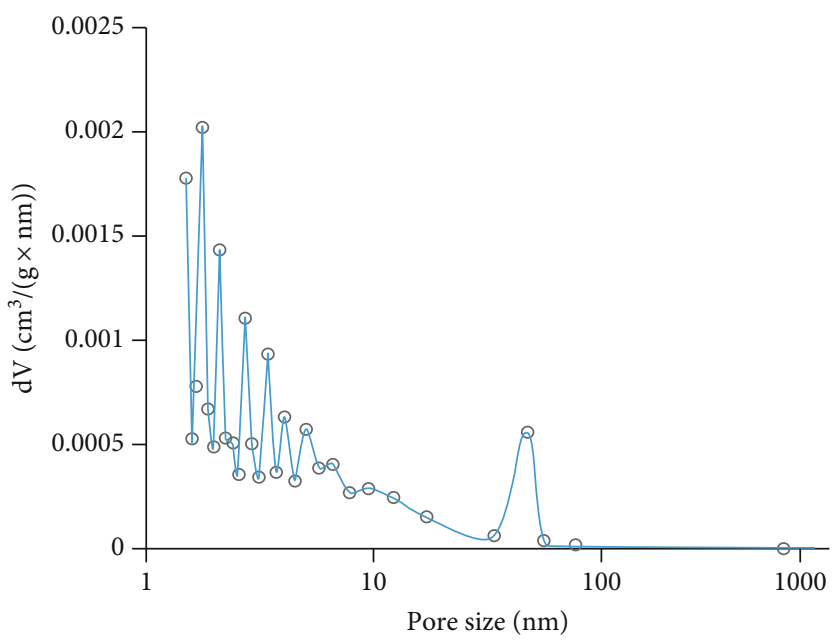

(b)

FIGURE 6: Typical NA experiment isothermal adsorption and desorption curves and pore size distribution of different lithofacies. (a) $4641 \mathrm{~m}$, isothermal adsorption and desorption curves. (b) $4636 \mathrm{~m}$, pore size distribution. (b1) $4639 \mathrm{~m}$, isothermal adsorption and desorption curves. (b2) $4639 \mathrm{~m}$, pore size distribution.

Our results consist of the research for the second member of Kongdian Formation (Ek2) in the Cangdong Sag, which proposed the mesopores have significant influences on surface area and pore volume [47]. However, for Ek2 shale, the micropores play the most important role in surface area, which may cause by the differences of $\mathrm{CO}_{2}$ and $\mathrm{N}_{2}$ gas adsorption experiments. However, it is no doubt that the significant contribution to surface area and pore volume of mesopores.

4.4. Movable and Adsorption Oil Calculation. Using Eq. (1), we obtained the TOY values of the samples with improved Rock-Eval pyrolysis data. The measured TOY values range from 3.13 to $7.09 \mathrm{mg} \mathrm{HC} / \mathrm{g}$ rock, with an average of $4.80 \mathrm{mg} \mathrm{HC} / \mathrm{g}$ rock; the calculated TOY value varies from
0.18 to $25.11 \mathrm{mg} \mathrm{HC/g}$ rock, and the average value is $9.44 \mathrm{mg} \mathrm{HC/g}$ rock.

Based on Eqs. (2) and (3), the movable hydrocarbon $S_{1 c}$ and adsorbed hydrocarbons $S_{a}$ were calculated. The $S_{a}$ ranges from 2.40 to $30.51 \mathrm{mg} \mathrm{HC/g}$ rock, and the average value is $11.92 \mathrm{mg} \mathrm{HC} / \mathrm{g}$ rock. And the $S_{1 c}$ varies from 0.19 to $5.78 \mathrm{mg}$ $\mathrm{HC} / \mathrm{g}$ rock, the average value is $2.19 \mathrm{mg} \mathrm{HC/g}$ rock.

4.5. Fractal Dimension. The fractal dimension calculation results and pore types are presented in Table 2. Most of the correlation coefficients $\left(R^{2}\right)$ are greater than 0.9 , which indicates that the pore network of the Es3 shale is fractal. In general, the fractal dimension $(D)$ ranges from 2.50 to 2.68. The fractal dimension of type II shale is significantly greater than type I shale. 
TABLE 1: Pore structure parameters of different pore systems.

\begin{tabular}{lcccccccc}
\hline $\begin{array}{l}\text { Reservoir } \\
\text { type }\end{array}$ & $\begin{array}{c}\text { Micropore SA } \\
\left(\mathrm{m}^{2} / \mathrm{g}\right)\end{array}$ & $\begin{array}{c}\text { Micropore PV } \\
\left(\mathrm{cm}^{3} / 100 \mathrm{~g}\right)\end{array}$ & $\begin{array}{c}\text { Mesopore SA } \\
\left(\mathrm{m}^{2} / \mathrm{g}\right)\end{array}$ & $\begin{array}{c}\text { Mesopore PV } \\
\left(\mathrm{cm}^{3} / 100 \mathrm{~g}\right)\end{array}$ & $\begin{array}{c}\text { Macropore SA } \\
\left(\mathrm{m}^{2} / \mathrm{g}\right)\end{array}$ & $\begin{array}{c}\text { Macropore PV } \\
\left(\mathrm{cm}^{3} / 100 \mathrm{~g}\right)\end{array}$ & $\begin{array}{c}\text { BJH SA } \\
\left(\mathrm{m}^{2} / \mathrm{g}\right)\end{array}$ & $\begin{array}{c}\text { BJH PV } \\
\left(\mathrm{cm}^{3} / 100 \mathrm{~g}\right)\end{array}$ \\
\hline Type I & $\begin{array}{c}0.066-0.386 \\
(0.218)\end{array}$ & $\begin{array}{c}0.0055-0.0337 \\
(0.0189)\end{array}$ & $\begin{array}{c}0.531-0.964 \\
(0.654)\end{array}$ & $\begin{array}{c}0.2174-0.2684 \\
(0.2366)\end{array}$ & $\begin{array}{c}0.012-0.019 \\
(0.013)\end{array}$ & $\begin{array}{c}0.0355-0.0871 \\
(0.0597)\end{array}$ & $\begin{array}{c}0.612-1.358 \\
(0.952)\end{array}$ & $\begin{array}{c}0.2810-0.3618 \\
(0.3152)\end{array}$ \\
Type II & 0.696 & 0.0586 & 1.971 & 0.7203 & 0.036 & 0.2047 & 2.703 & 0.9836 \\
\hline
\end{tabular}

Note: minimum-maximum (average value).

TABLe 2: Fractal dimensions of different lithofacies.

\begin{tabular}{lcccccccc}
\hline Reservoir type & $D_{\text {mic }}$ & $R^{2}$ & $D_{\text {meso }}$ & $R^{2}$ & $D_{\text {macro }}$ & $R^{2}$ & $D$ & $R^{2}$ \\
\hline Type I & 2.23 & 1.00 & 2.56 & 0.99 & 2.81 & 1.00 & 2.50 & 0.96 \\
Type I & 2.18 & 0.97 & 2.49 & 0.98 & 2.83 & 0.99 & 2.57 & 0.96 \\
Type I & 2.33 & 0.98 & 2.54 & 0.99 & 2.82 & 1.00 & 2.52 & 0.97 \\
Type I & 2.28 & 0.98 & 2.58 & 0.98 & 2.86 & 0.95 & 2.57 & 0.95 \\
Type I & 2.30 & 0.97 & 2.55 & 0.98 & 2.86 & 0.99 & 2.54 & 0.95 \\
Type I & 2.33 & 1.00 & 2.56 & 0.95 & 2.90 & 0.98 & 2.58 & 0.87 \\
Type II & 2.47 & 1 & 2.65 & 0.99 & 2.96 & 0.96 & 2.68 & 0.91 \\
\hline
\end{tabular}

From micropores to macropores, the corresponding fractal dimensions show an increasing trend. For the micropores, the fractal dimension $\left(D_{\text {mic }}\right)$ ranged from 2.18 to 2.47 , and the $D_{\text {mic }}$ of the type II shale is the highest. The fractal dimension of the mesopores $\left(D_{\text {mes }}\right)$ ranges from 2.49 to 2.65 , which is similar to that of the micropores. The fractal dimension of the macropores $\left(D_{\text {mac }}\right)$ varies from 2.81 to 2.96 , and the type II shale is significantly larger than type I.

\section{Discussion}

5.1. Relationships between the Fractal Dimension and Pore Structure Parameters. The relationships between the pore structural parameters (SA and PV) and the fractal dimension are shown in Figure 7. Theoretically, a larger fractal dimension indicates a more irregular and complex pore network. In general, the fractal dimensions have obvious positive correlations with the pore's structural parameters $\left(R^{2}\right.$ values of 0.74 and 0.70 for SA and PV, respectively), which means the fractal dimension can be used as a reliable index to quantify the heterogeneity of the Es3 shale's pore system. Moreover, a more heterogeneous and complex pore structure provides greater adsorption sites (SA) and storage space (PV), which is conducive to shale oil accumulation [33]. The type II shale has the highest fractal dimension, and thus, the highest SA and PV.

For the micropore and mesopore systems, the fractal dimensions are positively correlated with the pore structure parameters (Figures 7(b) and 7(c)). The fractal dimensions and pore structure parameters of the different type shales are significantly different. Type I has the lowest fractal dimension and pore structure parameters, and type II shale has the highest values. However, for the macropore system, although there are still positive correlations between the fractal dimension and pore structure parameters, the correlation coefficients are relatively low (Figure $7(\mathrm{~d})$ ).
There are different calculation models for getting fractal dimensions $[12,33]$, and the results are various. However, for our study area, only the results obtained by Eq. (5) are consistent of the definition of fractal dimension of pore surface and pore structure. This result means other models may not suit to describe the pore structure of lacustrine shale; therefore, the applicability of fractal theory to shale is still a worth exploring direction.

5.2. Influence of Mineral Composition on the Pore System. The mineral composition is an important factor controlling the structural properties of shale pore systems [12, 33]. In this study, we analyzed the effects of the shale mineral compositions on the pore structure parameters of the different pore systems. The correlation analysis results are presented in Figure 8. The results show that the clay mineral content strongly controls the pore structure properties and is the most important controlling factor, which is consistent with the Yanchang Formation shale in the Ordos Basin [48]. For all of the pore systems, the clay mineral content is positively correlated with the pore structure parameters. Since the dominant pore type in the study area is intercrystalline pores within clay minerals, a high clay mineral content is conducive to the formation of these pores, so the clay mineral content is positively correlated with SA and PV.

In contrast, the relationships between the siliceous and carbonate contents and the pore structure parameters are not significant. This phenomenon may be due to the following reasons. First, the quartz in the shales in eastern China is mainly formed by mechanically transported terrigenous detritus [49]. Furthermore, the clay minerals usually surround the quartz and carbonate; therefore, it is difficult to form granular support and primary intergranular pores, especially after the shales have undergone deep burial and strong diagenetic modification [49]. Moreover, few obvious grain supporting structures were observed in the Es3 shale during the SEM observations. Even though feldspar dissolution pores were detected in the SEM analysis, compared with the intercrystalline pores in the clay mineral, the amount of dissolution pores is relatively small. In addition, the dissolution of carbonates was not detected in the study area. Second, the SA of quartz and feldspar is 3.9 and $6.6 \mathrm{~m}^{2} / \mathrm{g}$, respectively, which is much lower than the SA of clay minerals $\left(200 \mathrm{~m}^{2} / \mathrm{g}\right.$ for an illite and smectite mixed layer) [49]. Therefore, the siliceous and carbonate minerals have fewer influences on the pore structure parameters.

5.3. Controlling Factors for Adsorption and Movable Oil. Due to the narrow $T_{\max }$ value distribution in this study, for 


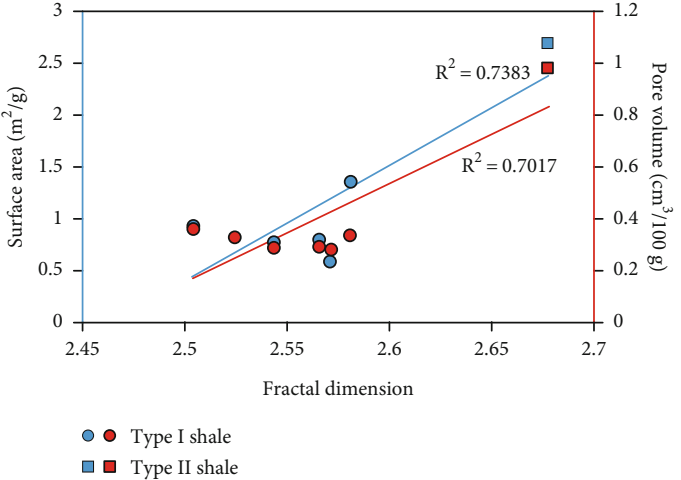

(a)

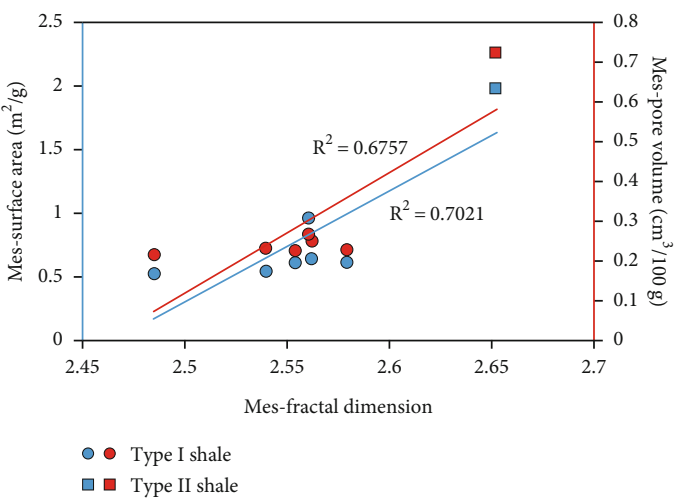

(c)

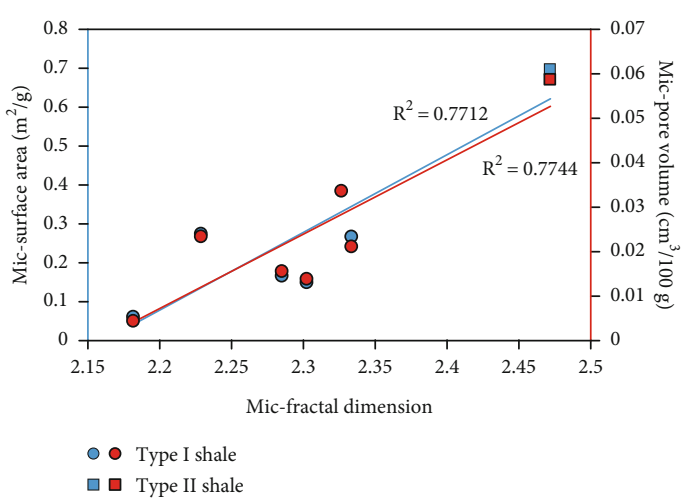

(b)

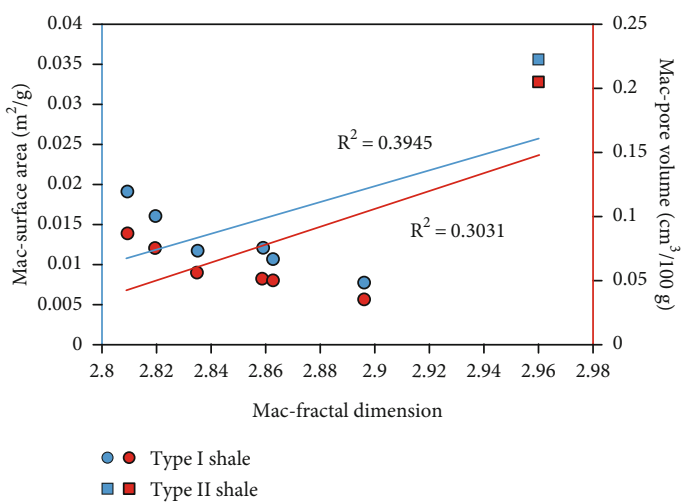

(d)

FIGURE 7: Scatter diagram of fractal dimensions of different pore systems versus SA and PV.

further discussion, we cited some data from [28], and due to the similar kerogen type, we use the movable oil correction models proposed in this study to process the original data.

The adsorption oil calculation model in our study is proposed by TOC content; therefore, the organic matter abundance is strongly positively correlated with the adsorption oil content. Meanwhile, previous study has shown that kerogen makes a major contribution to the oil adsorption ability [50]. In the case of consistent kerogen types, the TOC content represents the organic matter abundance and the kerogen amount. Therefore, TOC content is proportional to the adsorbed oil content, which also proves the rationality of our adsorbed oil calculation model. Meanwhile, as can be detected in Figure 9, the $S_{1 c}$ and TOC are positively correlating, the correlation of data in this paper $\left(R^{2}=0.79\right)$ is higher than the data from [28] $\left(R^{2}=0.20\right)$, the positive correlation between movable oil, and TOC is mainly due to the TOC content represents the abundance of organic matter. High organic matter abundance provides strong hydrocarbon generation capacity for source rocks, although it is also accompanied by a greater hydrocarbon adsorption ability. The Es3 is the main source rocks in the study area which contributes more than $50 \%$ of oil and gas in the sag [51], indicating that the majority of Es3 source rock samples can meet the kerogen adsorption; therefore, strong hydrocarbon generation capacity can provide more movable oil amount.
According to Figure 10, with an increase of $T_{\text {max }}$, adsorbed and movable oil generally raised first and then decreased. Although the trends are similar, the principle of this phenomenon is completely different. Previous studies have shown that with the increase of thermal maturity, the kerogens' oil adsorption capacity gradually decreases, and the reason for this phenomenon is that when the source rock stay in the early mature stage, the generated oil cannot meet the kerogen absorption. In this phase, the absorption capacity is much larger than generated hydrocarbon amount, and the generated oil is adsorbed by kerogen. With source rock evolution, the hydrocarbon generation potential increases rapidly; when the generated oil amount exceeds the maximum hydrocarbon adsorption ability, the adsorbed oil amount is consistent with the trend of adsorption capacity. For movable oil, after the source rock meets the kerogen adsorption, the generated oil will migrate to pores and fractures, and these oils can be identified as movable oil. When oil fills the pores and fractures, it will expel from source rocks, this point is defined as hydrocarbon expulsion threshold [23], and the movable oil content begins decreasing at this point.

Mineral composition plays an important role in controlling both movable and adsorbed oil amounts [2]. With quartz content increase, the movable and absorbed oil contents increase initially and decrease afterward (Figure 11). Compared with other minerals (like clay minerals), the hydrocarbon adsorption ability of quartz grains is not 

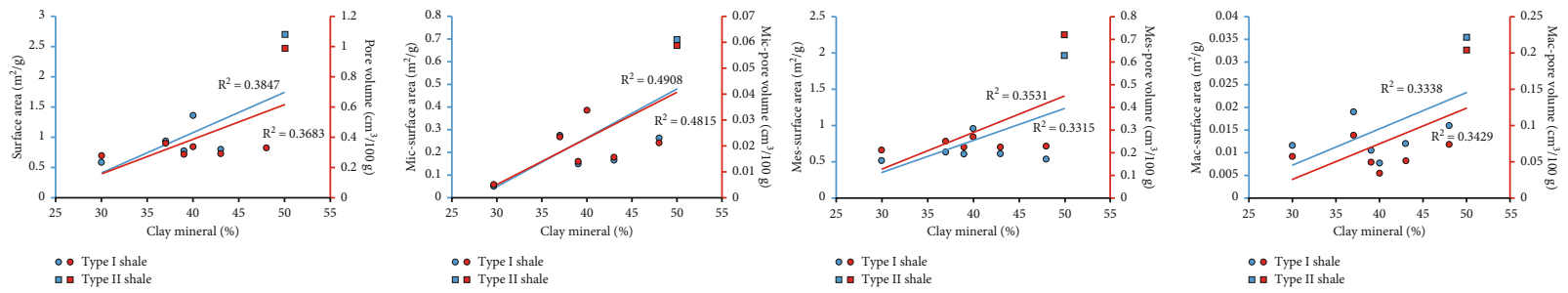

$$
\begin{aligned}
& \text { ‥ Type I shale } \\
& \text { घ Type II shale }
\end{aligned}
$$

․ Type I shale
घ $\quad$ Type II shale
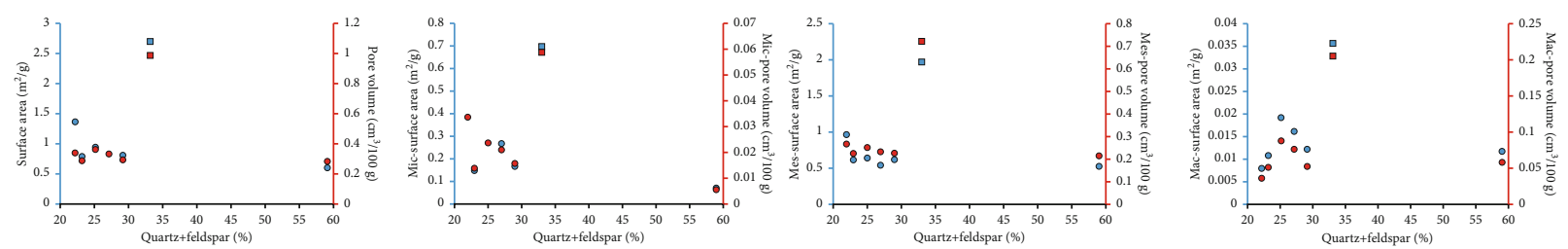

ㅂ. Type I shale
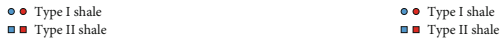

$\because$ Type I shale
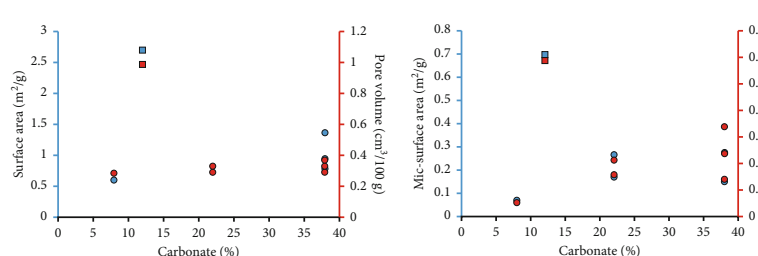

पष Type II shal

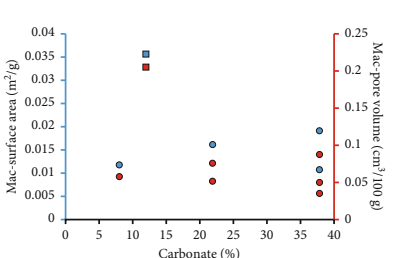

ㅇ Type I shale
घ Type II shale

- Type I shale
घ Type II shale

$\because$ Type I shale

-. Type I shale

FIGURE 8: Scatter diagram of mineral composition versus SA and PV of different pore systems.

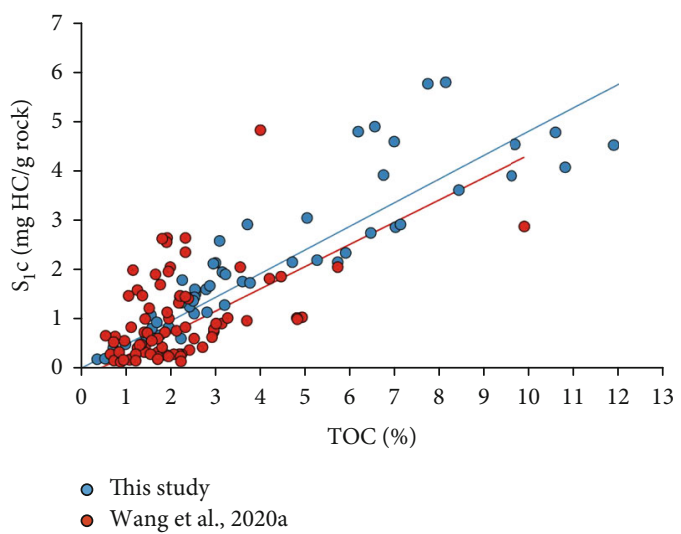

FIGURE 9: Scatter diagram showing TOC content and movable oil contents.

competitive [50]. The influence of quartz on adsorption oil amount is mainly reflected by the effect of quartz on TOC content. High quartz content indicates the increase of terrigenous debris inputting, and a certain amount of terrigenous debris input can provide nutrients to sedimentary water, which is conducive to organic matter accumulation. However, excessive input of terrigenous materials will lead to the decrease of organic matter concentration, which is not favorable to the TOC accumulation, and this similar trend also reflects the adsorption oil amount. The relationship between quartz and movable oil is relatively complex. First, the increase of quartz content can improve the development of primary pores and provide reservoir space for movable oil (Figures 5(a) and 5(e)), and even the impact is limited. Sec- ond, the similar principle of adsorption oil, TOC changes also affect the content of movable oil, and the final trend reflects that the effect of TOC content on movable oil is more obvious than that of primary pores development.

Clay mineral is the primary mineral in the study area, and its influence on adsorption and movable oil content should not be ignored. The content of clay minerals can characterize the preservation conditions of organic matter in the sedimentary environment, and high clay mineral content represents a reducing, deep-water sedimentary environment, which is conducive to the preservation and development of organic matter. Therefore, the clay mineral content and TOC content first showed a positive correlation (Figure 12). With the increase of clay mineral content, reflecting the improvement of the quietness of sedimentary environment, inputted terrestrial materials and nutrients cannot reach the sedimentary water, which is not conducive to the accumulation of organic matter and leads to the decrease of TOC content, thus, the trend of adsorbed oil is increased first and then decreased. Meanwhile, clay minerals have the highest specific surface area and the strongest oil adsorption capacity. Therefore, with the increase of clay minerals, oil adsorption capacity gradually increased. The correlation between clay minerals and adsorbed oil caused by the superposition of the two effects is not very obvious, but in general, there is a weak positive correlation (Figure 12). For movable oil, the trend of movable oil is completely different from adsorbed oil, which is mainly controlled by the change of TOC content. Meanwhile, as mentioned before, increasing clay minerals brings stronger oil adsorption capacity, resulting in the decrease of movable oil content. 


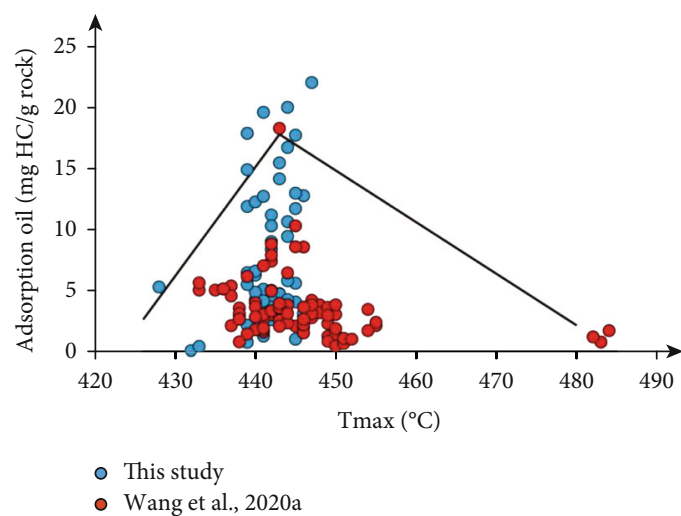

(a)

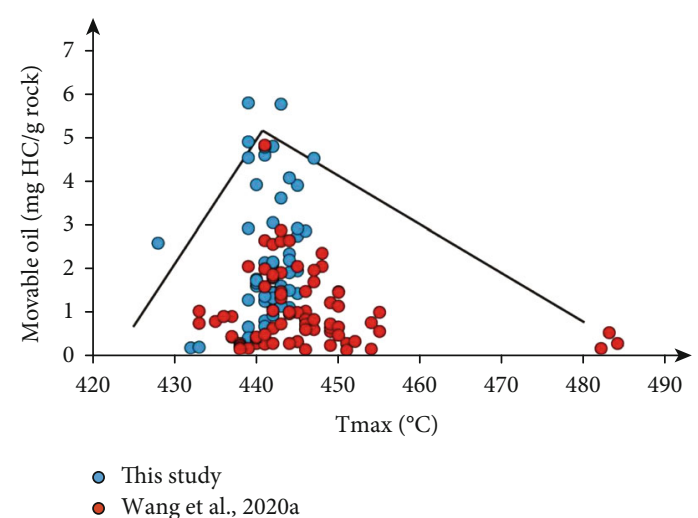

(b)

FIGURE 10: Scatter diagram showing thermal maturity of adsorption and movable oil contents.

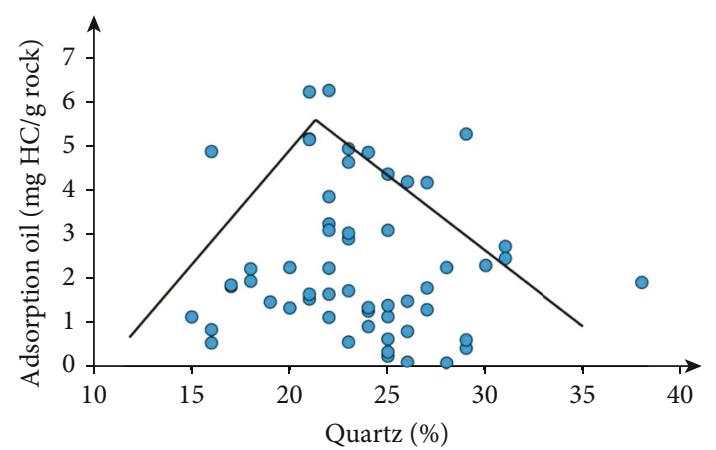

(a)

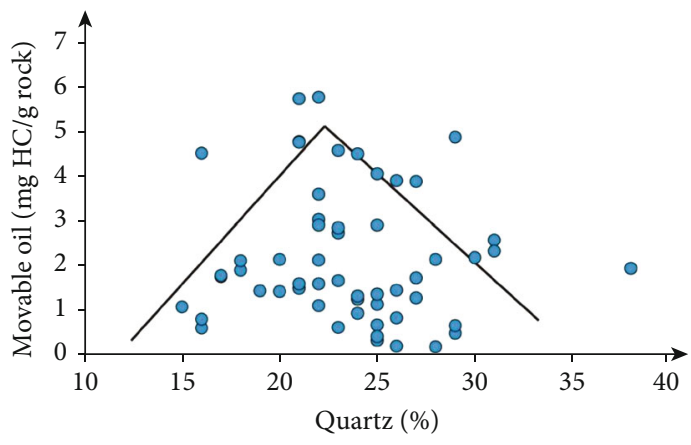

(b)

FIGURE 11: Scatter diagram of mineral composition versus TOY reflecting influences of mineral composition to shale oil retention.

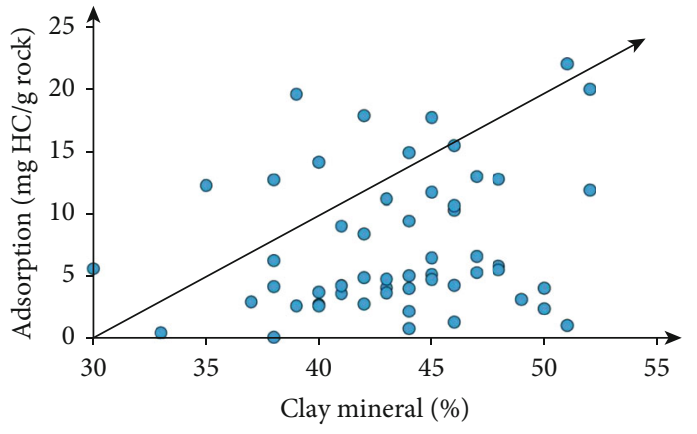

(a)

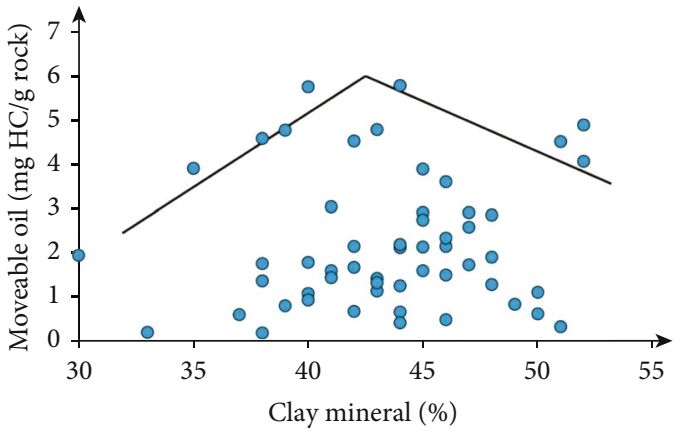

(b)

FIgURE 12: Scatter diagram showing relationships between clay mineral content and adsorption and movable oil contents.

\section{Conclusions}

In this study, based on programmed and improved RockEval pyrolysis, TOC content measurements, SEM observations, and NA experiments, a systematic evaluation of the mineral composition, geochemical feature, pore structure, and oil contents of the Es3 shale in the Nanpu Sag was conducted. The geochemical features of the Es3 shale are relatively good, and they can be classified as a set of high- quality source rocks (average TOC of $4.2 \%$, mainly type II kerogen, and in the mature stage).

According to the SEM observations and NA experiments, the pore system structure was qualitative and quantitively described. Intercrystalline and intragranular pores and microfractures were observed, and intercrystalline pores dominated the pore system. Moreover, the mesopores contribute most of the SA and PV of the samples (average contribution rates of 74.7 and $75.0 \%$, respectively). The fractal 
dimension was calculated to quantify the complex and heterogeneous pore networks. The fractal dimension has relatively strong positive correlations with the pore structure parameters. The type II shale has the highest fractal dimension. The pore structure parameters are correlated with the mineral composition. Our results show that the clay mineral content is the most important factor controlling the pore structure parameters. A high clay content indicates high $\mathrm{SA}$ and PV, and the siliceous and carbonate contents have no obvious correlation with the pore structure parameters.

Proposing a numerical movable and adsorption oil contents calculation model, and utilize it to calculate oil contents of samples only with programmed Rock-Eval pyrolysis experiment. Our results show that the movable and adsorption oil contents are controlled by TOC content, thermal maturity, and mineral composition. The TOC content is the dominant factor controlling the movable and adsorption oil contents, and other factors' impact also cannot be ignored.

\section{Data Availability}

The [DATA TYPE] data used to support the findings of this study are included within the article.

\section{Conflicts of Interest}

The authors declare that they have no conflicts of interest.

\section{Authors' Contributions}

Enze Wang did the conception and design of the work and original draft writing. Gang Chen did the original data acquisition, design of the work, and funding acquisition. Hanqi Li did the revision of the draft according to reviewer comments (result and discussion section), data analysis, and language polishing. Yanchen Song did the data analysis and revision of the draft according to reviewer comments (result and discussion section). Jianwei Wang did the original data acquisition. Zhuoya $\mathrm{Wu}$ did the review of original draft, revision of the draft according to reviewer comments (introduction and result section), and data interpretation. Yue Feng did the data analysis and interpretation and reviewed the draft.

\section{Acknowledgments}

This study was financially supported by the National Basic Research Program of China (2016ZX05006-006). The PetroChina Jidong Oilfield Company provided the data. We sincerely appreciate their permission to publish this paper.

\section{References}

[1] C. R. Clarkson, N. Solano, R. M. Bustin et al., "Pore structure characterization of North American shale gas reservoirs using USANS/SANS, gas adsorption, and mercury intrusion," Fuel, vol. 103, pp. 606-616, 2013.

[2] T. Hu, X. Q. Pang, F. J. Jiang et al., "Movable oil content evaluation of lacustrine organic-rich shales: methods and a novel quantitative evaluation model," Earth Science Reviews, vol. 214, p. 103545, 2021.

[3] D. M. Jarvie, R. Hill, T. E. Ruble, and R. M. Pollastro, "Unconventional shale-gas systems: the Mississippian Barnett shale of north-central Texas as one model for thermogenic shale-gas assessment," AAPG Bulletin, vol. 91, no. 4, pp. 475-499, 2007.

[4] B. E. Law and J. B. Curtis, "Introduction to unconventional petroleum systems," AAPG Bulletin, vol. 86, no. 11, pp. 18511852, 2002.

[5] E. Z. Wang, C. R. Li, Y. Feng et al., "Novel method for determining the oil moveable threshold and an innovative model for evaluating the oil content in shales," Energy, vol. 239, article no. 121848, 2022.

[6] Y. Feng, X. M. Xiao, E. Z. Wang, J. Sun, and P. Gao, “Oil retention in shales: a review of the mechanism, controls and assessment," Frontiers in Earth Science, vol. 9, article no. 720839, 2021.

[7] D. J. K. Ross and R. M. Bustin, "Characterizing the shale gas resource potential of Devonian-Mississippian strata in the Western Canada Sedimentary Basin: application of an integrated formation evaluation," AAPG Bulletin, vol. 92, no. 1, pp. 87-125, 2008.

[8] D. M. Jarvie, "Shale resource systems for oil and gas: part 1shale-gas resource systems," in Shale Reservoirs Giant Resources for the 21st Century, J. A. Breyer, Ed., vol. 97 of Am. Assoc. Petrol. Geol. Mem, pp. 69-87, 2012.

[9] D. M. Jarvie, "Shale resource systems for oil and gas: part 2shale-oil resource systems," in Shale Reservoirs Giant Resources for the 21st Century, J. A. Breyer, Ed., vol. 97 of Am. Assoc. Petrol. Geol. Mem, pp. 89-119, 2012.

[10] R. G. Loucks, R. M. Reed, S. C. Ruppel, and D. M. Jarvie, "Morphology, genesis, and distribution of nanometer-scale pores in siliceous mudstones of the Mississippian Barnett Shale," Journal of Sedimentary Research, vol. 79, no. 12, pp. 848-861, 2009.

[11] T. F. T. Rexer, M. J. Benham, A. C. Aplin, and K. M. Thomas, "Methane adsorption on shale under simulated geological temperature and pressure conditions," Energy \& Fuels, vol. 27, no. 6, pp. 3099-3109, 2013.

[12] X. H. Shao, X. Q. Pang, Q. W. Li et al., "Pore structure and fractal characteristics of organic-rich shales: a case study of the lower Silurian Longmaxi shales in the Sichuan Basin, SW China," Marine and Petroleum Geology, vol. 80, pp. 192-202, 2017.

[13] K.-G. Zink, G. Scheeder, H. L. Stueck, S. Biermann, and M. Blumenberg, "Total shale oil inventory from an extended Rock-Eval approach on non-extracted and extracted source rocks from Germany," International Journal of Coal Geology, vol. 163, pp. 186-194, 2016.

[14] M. A. Abrams, C. Gong, C. Garnier, and M. A. Sephton, "A new thermal extraction protocol to evaluate liquid rich unconventional oil in place and in-situ fluid chemistry," Marine and Petroleum Geology, vol. 88, pp. 659-675, 2017.

[15] L. H. Hou, X. Luo, W. X. Han, S. H. Lin, Z. L. Pang, and J. Z. Liu, "Geochemical evaluation of the hydrocarbon potential of shale oil and its correlation with different minerals-a case study of the TYP shale in the Songliao Basin, China," Energy and Fuels, vol. 34, no. 10, pp. 11998-12009, 2020.

[16] M. W. Li, Z. H. Chen, X. X. Ma et al., "Shale oil resource potential and oil mobility characteristics of the Eocene- Oligocene Shahejie Formation, Jiyang Super-Depression, Bohai Bay 
Basin of China," International Journal of Coal Geology, vol. 204, pp. 130-143, 2019.

[17] Q. G. Jiang, M. W. Li, M. H. Qian et al., "Quantitative characterization of shale oil in different occurrence states and its application," Petroleum Geology \& Experiment, vol. 38, no. 6, pp. 842-849, 2016, (in Chinese with English Abstract).

[18] M. Wang, R. Ma, J. Li et al., "Occurrence mechanism of lacustrine shale oil in the Paleogene Shahejie Formation of Jiyang Depression, Bohai Bay Basin, China," Petroleum Exploration and Development, vol. 46, no. 4, pp. 833-846, 2019.

[19] G. R. L. Chalmers, D. J. K. Ross, and R. M. Bustin, "Geological controls on matrix permeability of Devonian Gas Shales in the Horn River and Liard basins, northeastern British Columbia, Canada," International Journal of Coal Geology, vol. 103, no. 23, pp. 120-131, 2012.

[20] B. B. Mandelbrot, D. E. Passoja, and A. J. Paullay, "Fractal character of fracture surfaces of metals," Nature, vol. 308, pp. 721-722, 1984.

[21] P. Pfeiferper and D. Avnir, "Chemistry nonintegral dimensions between two and three," The Journal of Chemical Physics, vol. 79, no. 7, pp. 3369-3558, 1983.

[22] C. E. Krohn, "Fractal measurements of sandstones, shales, and carbonates," Journal of Geophysical Research, vol. 93, B4, pp. 3297-3305, 1988.

[23] E. Z. Wang, Y. Feng, G. Y. Liu, S. R. Chen, Z. Y. Wu, and C. R. $\mathrm{Li}$, "Hydrocarbon source potential evaluation insight into source rocks-a case study of the first member of the Paleogene Shahejie Formation, Nanpu Sag, NE China," Energy Reports, vol. 7, pp. 32-42, 2021.

[24] Y. Dong, L. Xiao, H. Zhou et al., "The tertiary evolution of the prolific Nanpu Sag of Bohai Bay Basin, China: constraints from volcanic records and tectono-stratigraphic sequences," Geological Society of America Bulletin, vol. 122, no. 3-4, pp. 609-626, 2010.

[25] E. Z. Wang, G. Y. Liu, X. Q. Pang et al., "Sedimentology, diagenetic evolution, and sweet spot prediction of tight sandstone reservoirs: a case study of the third member of the Upper Paleogene Shahejie Formation, Nanpu Sag, Bohai Bay Basin, China," Journal of Petroleum Science and Engineering, vol. 186, p. 106718, 2020.

[26] E. Z. Wang, X. Q. Pang, X. D. Zhao et al., "Characteristics, diagenetic evolution, and controlling factors of the Es1 deep burial high-quality sandstone reservoirs in the PG2 oilfield, Nanpu Sag, Bohai Bay Basin, China," Geological Journal, vol. 55, no. 4, pp. 2403-2419, 2020.

[27] M. B. Allen, D. Macdonald, Z. Xun, S. Vincent, and C. BrouetMenzies, "Early Cenozoic two-phase extension and late Cenozoic thermal subsidence and inversion of the Bohai Basin, northern China," Marine and Petroleum Geology, vol. 14, no. 7-8, pp. 951-972, 1997.

[28] E. Z. Wang, G. Y. Liu, X. Q. Pang et al., “An improved hydrocarbon generation potential method for quantifying hydrocarbon generation and expulsion characteristics with application example of Paleogene Shahejie Formation, Nanpu Sag, Bohai Bay Basin," Marine and Petroleum Geology, vol. 112, p. 104106, 2020.

[29] Y. Guo, X. Pang, Y. Dong, Z. Jiang, D. Chen, and F. Jiang, "Hydrocarbon generation and migration in the Nanpu Sag, Bohai Bay Basin, eastern China: insight from basin and petroleum system modeling," Journal of Asian Earth Sciences, vol. 77, no. 15, pp. 140-150, 2013.
[30] E. Z. Wang, Z. J. Wang, X. Q. Pang et al., "Key factors controlling hydrocarbon enrichment in a deep petroleum system in a terrestrial rift basin-a case study of the uppermost member of the upper Paleogene Shahejie Formation, Nanpu Sag, Bohai Bay Basin, NE China," Marine and Petroleum Geology, vol. 107, pp. 572-590, 2019.

[31] E. Z. Wang, G. Y. Liu, X. Q. Pang, C. Q. Li, and Z. Y. Wu, “Diagenetic evolution and formation mechanisms of middle to deep clastic reservoirs in the Nanpu sag, Bohai Bay Basin, East China," Petroleum Exploration and Development, vol. 47, no. 2, pp. 343-356, 2020.

[32] J. Espitalié, M. Madec, B. Tissot, J. J. Mennig, and P. Leplat, Source Rock Characterization Method for Petroleum Exploration (OTC 2935), In Offshore Technology Conference. OTC, Houston, Texas, 1977.

[33] A. Q. Jia, D. F. Hu, S. He et al., "Variations of pore structure in organic-rich shales with different lithofacies from the Jiangdong block, fuling shale gas field, SW China: insights into gas storage and pore evolution," Energy \& Fuels, vol. 34, no. 10, pp. 12457-12475, 2020.

[34] C. N. Zou, Z. Yang, R. K. Zhu et al., "Geologic significance and optimization technique of sweet spots in unconventional shale systems," Journal of Asian Earth Sciences, vol. 178, pp. 3-19, 2019.

[35] J. Zou, W. Chen, D. Yang, J. Yuan, and Y. Y. Jiao, "Fractal characteristics of the anisotropic microstructure and pore distribution of low-rank coal," AAPG Bulletin, vol. 103, no. 6, pp. 1297-1319, 2019.

[36] R. Yang, S. He, J. Yi, and Q. Hu, "Nano-scale pore structure and fractal dimension of organic-rich Wufeng- Longmaxi shale from Jiaoshiba area, Sichuan Basin: investigations using FE- SEM, gas adsorption and helium pycnometry," Marine and Petroleum Geology, vol. 70, pp. 27-45, 2016.

[37] R. G. Loucks, R. M. Reed, S. C. Ruppel, and U. Hammes, "Spectrum of pore types and networks in mudrocks and a descriptive classification for matrix-related mudrock pores," AAPG Bulletin, vol. 96, no. 6, pp. 1071-1098, 2012.

[38] R. J. Hill, D. M. Jarvie, J. Zumberge, M. Henry, and R. M. Pollastro, "Oil and gas geochemistry and petroleum systems of the Fort Worth Basin,” AAPG Bulletin, vol. 91, no. 4, pp. 445-473, 2007.

[39] R. Gottardi, L. M. Adams, D. Borrok, and B. Teixeira, "Hydrocarbon source rock characterization, burial history, and thermal maturity of the Steele, Niobrara and Mowry Formations at Teapot Dome, Wyoming," Marine and Petroleum Geology, vol. 100, pp. 326-340, 2019.

[40] W. Y. Wang, X. Q. Pang, Z. X. Chen et al., "Improved methods for determining effective sandstone reservoirs and evaluating hydrocarbon enrichment in petroliferous basins," Applied Energy, vol. 261, no. 1, p. 114457, 2020.

[41] D. F. Huang and J. C. Li, "Quantitative evaluation of source rocks," in Continental Hydrocarbon Generation in China, pp. 175-176, Petroleum Industry Press, Beijing, 1982, (in Chinese).

[42] V. Agrawal and S. Sharma, "Molecular characterization of kerogen and its implications for determining hydrocarbon potential, organic matter sources and thermal maturity in Marcellus Shale," Fuel, vol. 228, pp. 429-437, 2018.

[43] K. E. Peters and M. R. Cassa, "Applied source-rock geochemistry," American Association of Petroleum Geologists Memoirs, vol. 60, pp. 93-120, 1994. 
[44] J. Espitalié, "Use of Tmax as a maturation index for different types of organic matter-comparison with vitrinite reflectance," in Thermal Modeling in Sedimentary Basins, J. Burrus, Ed., pp. 475-496, Editions Technip, Paris, 1985.

[45] Z. Y. Wu, X. Z. Zhao, E. Z. Wang et al., "Sedimentary environment and organic enrichment mechanisms of lacustrine shale: a case study of the Paleogene Shahejie Formation, Qikou Sag, Bohai Bay Basin," Palaeogeography Palaeoclimatology Palaeoecology, vol. 573, p. 110404, 2021.

[46] X. Z. Zhao, L. H. Zhou, X. G. Pu et al., "Geological characteristics and exploration breakthrough of shale oil in Member 3 of Shahejie Formation of Qibei Subsag, Qikou Sag," Acta Petrolei Sinica, vol. 41, no. 6, pp. 643-657, 2020, (in Chinese with English abstract).

[47] Y. Deng, X. G. Pu, S. Y. Chen et al., "Characteristics and controlling factors of fine-grained mixed sedimentary rocks reservoirs: a case study of the $2^{\text {nd }}$ member of Kongdian Formation in Cangdong depreesion, Bohai Bay Basin," Journal of China University of Mining and Technology, vol. 48, no. 6, pp. 1301-1316, 2019, (in Chinese with English abstract).

[48] H. J. Guo, R. L. He, W. L. Jia et al., "Pore characteristics of lacustrine shale within the oil window in the Upper Triassic Yanchang Formation, southeastern Ordos Basin, China," Marine and Petroleum Geology, vol. 91, pp. 279-296, 2018.

[49] H. K. Nie, P. X. Zhang, R. K. Bian, X. L. Wu, and C. B. Zhai, "Oil accumulation characteristics of China continental shale," Earth Science Frontiers, vol. 23, no. 2, pp. 55-62, 2016, (in Chinese with English abstract).

[50] Z. Li, Y. R. Zou, X. Y. Xu, J. N. Sun, M. Li, and P. Peng, "Adsorption of mudstone source rock for shale oil - Experiments, model and a case study," Organic Geochemistry, vol. 92, pp. 55-62, 2016.

[51] H. J. Zheng, Y. X. Dong, G. Y. Zhu, X. D. Wang, and Y. Xiong, "High-quality source rocks in Nanpu Sag," Petroleum Exploration and Development, vol. 34, no. 4, pp. 385-391, 2007. 